\title{
A Role for a Sterol and a Sterol Precursor in the Bacterium Rhodopseudomonas palustris
}

\author{
By S. AARONSON \\ Haskins Laboratories, New York, N.Y. 10017, U.S.A.
}

(Received 5 June 1964)

\begin{abstract}
SUMMARY
The multiplication of the purple photosynthetic bacterium Rhodopseudomonas palustris is inhibited by the hypocholesteraemic agents benzmalecene and triparanol. This inhibition is annulled by oleic acid, ergosterol, squalene, farnesol and lanosterol, in that order, but not by mevalonic acid, geranyl acetate, palmitic or stearic acids. Only oleic acid annuls the inhibition in higher concentrations of the inhibitors. Ergosterol and squalene, while not effective against higher concentrations of inhibitor, spared the annulment by oleic acid. An unknown interaction between oleic acid and sterols or their precursors is suggested.
\end{abstract}

\section{INTRODUCTION}

The existence of sterols in bacteria is questionable. The evidence was reviewed by Asselineau (1962) and Fiertel \& Klein (1959); relatively few bacteria have been analysed. Various compounds block different sites in the synthesis of cholesterol in mammals (Holmes \& Di Tullio, 1962). Two of these, benzmalecene and triparanol, inhibited protozoa (Aaronson, Bensky, Shifrine \& Baker, 1962) and have been studied here to see whether they uncover sterol or sterol-related functions in bacteria, much as sulphanilamide uncovered $p$-aminobenzoic acid (Woods, 1940).

\section{METHODS}

Rhodopseudomonas palustris was grown by methods described elsewhere (Keane, Zahalsky, Hutner \& Lubart, 1963). Experimental cultures were incubated for 5 days at $28^{\circ}$ under incandescent and fluorescent lamps.

The chemicals used were commercial grades; the fatty acids (99\% pure by gasliquid chromatography) were purchased from Applied Science Laboratories, State College, Pa., U.S.A., or the Hormel Institute, Austin, Minn., U.S.A.

Benzmalecene was supplied by Dr D. Hendlin (Merck, Sharp \& Dohme Research Laboratories, Rahway, N. J.) and triparanol by Dr F. J. Murray (W. S. Merrell Co., Cincinnati, Ohio, U.S.A.). Benzmalecene was dissolved in alkaline water and triparanol was dissolved in $95 \%(\mathrm{v} / \mathrm{v})$ ethanol in water. The concentrations of ethanol used were not toxic.

\section{RESULTS}

Inhibition of Rhodopseudomonas palustris multiplication by benzmalecene and triparanol was annulled by crude lipid preparations: crude lecithin and TEM-4 (the diacetyl tartaric acid ester of tallow glycerides) and by the following compounds: 
oleic acid, ergosterol, squalene, farnesol, lanosterol in that order, but not by mevalonic acid, geranyl acetate, palmitic or stearic acids (see Table 1). Oleic acid was the most effective compound in annulling inhibitions at the higher concentrations of the inhibitors, while squalene and ergosterol were almost as effective as oleic acid at low inhibitory concentrations but not at higher concentrations of benzmalecene and triparanol (Tables 2,3). Only oleic acid was effective at higher concentrations. At a higher concentration of benzmalecene, squalene or ergosterol while ineffective by themselves spared the annulment by oleic acid. Similar results were obtained with triparanol.

Table 1. Annulment by lipids of inhibition of growth of Rhodopseudomonas palustris produced by hypocholesteraemic agents

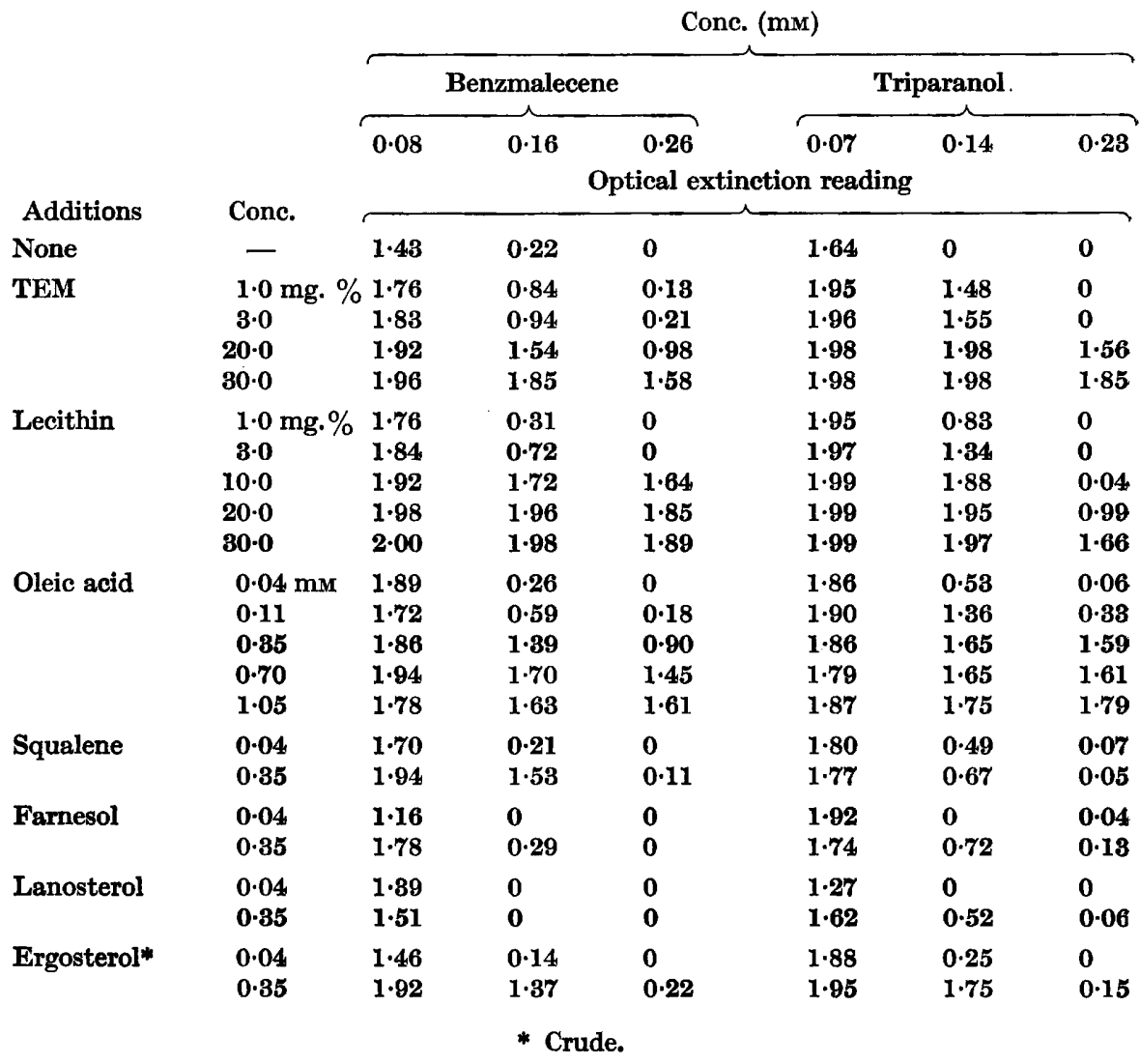

\section{DISCUSSION}

Evidence for sterols in bacteria is meagre and unsatisfactory; this information derives from rather non-specific reactions, e.g. the Liebermann-Burchard (L-B) reaction, and on bacteria grown in ill-defined and often sterol-containing media. Bacteria which do not require sterols for growth may nevertheless accumulate unchanged sterols (Smith \& Rothblatt, 1960; Rebel \& Mandel, 1962). Moreover, the methods used to detect sterols in bacteria were not flawless: saturated sterols do not give a colour reaction (L-B) and slight structural changes in the sterol 
molecule render it unprecipitable by digitonin (Bergmann, 1962). The availability of compounds which inhibit sterol biosynthesis in mammals (Holmes \& Di Tullio, 1962) allowed us to test the sterol-inhibiting properties of these compounds on bacteria in the hope of demonstrating a sterol requirement by inhibition analysis. In mammals benzmalecene inhibits early in sterol synthesis at the reaction sequence which converts isopentylpyrophosphate into squalene; triparanol inhibits a terminal step: reduction of desmosterol to cholesterol (Holmes \& Di Tullio, 1962).

Table 2. Interaction between oleic acid and squalene in annulling inhibition of growth of Rhodopseudomonas palustris

\begin{tabular}{|c|c|c|c|c|c|}
\hline \multirow{2}{*}{ Compound } & \multirow{2}{*}{ Conc. (mM) } & \multicolumn{4}{|c|}{ Squalene (mM) } \\
\hline & & \multicolumn{4}{|c|}{ Optical extinction reading } \\
\hline Benzmalecene & $0 \cdot 16$ & 0.47 & 0.65 & $1 \cdot 53$ & $2 \cdot 13$ \\
\hline Benzmalecene + oleic acid & $\left\{\begin{array}{l}0 \cdot 04 \\
0 \cdot 11 \\
0 \cdot 35 \\
1 \cdot 05\end{array}\right.$ & $\begin{array}{l}0.80 \\
1.46 \\
1.86 \\
2.13\end{array}$ & $\begin{array}{l}1 \cdot 68 \\
1 \cdot 88 \\
2 \cdot 23 \\
2 \cdot 40\end{array}$ & $\begin{array}{l}2 \cdot 24 \\
2 \cdot 38 \\
2 \cdot 58 \\
2 \cdot 50\end{array}$ & $\begin{array}{l}2 \cdot 46 \\
2 \cdot 54 \\
2 \cdot 62 \\
2 \cdot 50\end{array}$ \\
\hline Benzmalecene & 0.26 & $\mathbf{0}$ & $\mathbf{0}$ & $\mathbf{0}$ & $\mathbf{0}$ \\
\hline Benzmalecene + oleic acid & $\left\{\begin{array}{l}0.04 \\
0.11 \\
0.35 \\
1.05\end{array}\right.$ & $\begin{array}{l}0 \cdot 18 \\
0 \cdot 28 \\
1 \cdot 17 \\
1.60\end{array}$ & $\begin{array}{l}0.42 \\
0.70 \\
1.29 \\
1.82\end{array}$ & $\begin{array}{l}0.76 \\
0 \cdot 64 \\
1 \cdot 75 \\
1.97\end{array}$ & $\begin{array}{l}\mathbf{2 \cdot 3 9} \\
\mathbf{2} \cdot 57 \\
\mathbf{2 \cdot 5 6} \\
\mathbf{2} \cdot 40\end{array}$ \\
\hline Triparanol & $0 \cdot 14$ & $\mathbf{0}$ & $0 \cdot 16$ & $0 \cdot 47$ & 0.97 \\
\hline Triparanol + oleic acid & $\left\{\begin{array}{l}0.04 \\
0 \cdot 11 \\
0.35 \\
1 \cdot 05\end{array}\right.$ & $\begin{array}{l}0 \cdot 96 \\
2 \cdot 50 \\
2 \cdot 64 \\
2 \cdot 49\end{array}$ & $\begin{array}{l}1.59 \\
2 \cdot 4.6 \\
2 \cdot 58 \\
2.53\end{array}$ & $\begin{array}{l}1 \cdot 82 \\
\mathbf{2} \cdot 51 \\
\mathbf{2} \cdot 61 \\
\mathbf{2} \cdot 40\end{array}$ & $\begin{array}{l}1 \cdot 94 \\
2 \cdot 46 \\
2 \cdot 55 \\
2 \cdot 32\end{array}$ \\
\hline Triparanol & 0.23 & $0 \cdot 08$ & $0 \cdot 06$ & 0.06 & $0 \cdot 04$ \\
\hline Triparanol + oleic acid & $\left\{\begin{array}{l}0 \cdot 04 \\
0 \cdot 11 \\
0 \cdot 35 \\
1 \cdot 05\end{array}\right.$ & $\begin{array}{l}0.02 \\
0 \cdot 30 \\
2 \cdot 58 \\
2 \cdot 48\end{array}$ & $\begin{array}{l}\mathbf{0 . 0 5} \\
0.55 \\
2.57 \\
\mathbf{2 . 4 8}\end{array}$ & $\begin{array}{l}0.08 \\
0.46 \\
2.58 \\
2.44\end{array}$ & $\begin{array}{l}0 \cdot 06 \\
0 \cdot 55 \\
2 \cdot 46 \\
2 \cdot 38\end{array}$ \\
\hline
\end{tabular}

In Rhodopseudomonas palustris the inhibition produced by low concentrations of benzmalecene or triparanol was annulled almost as well by squalene and ergosterol as by oleic acid. At higher concentrations of these inhibitors only oleic was effective; squalene and ergosterol, while inactive alone, spared the oleic acid. These results suggest a metabolic role for the ergosterol and the sterol precursor, squalene, in this bacterium as well as a curious and as yet unexplained interaction between oleic acid and the sterols. Jensen (1962) identified a triterpene, paluol, in two strains of R. palustris. Possibly benzmalecene and triparanol inhibit the synthesis of paluol, an inhibition presumably annulled by squalene or ergosterol. Isotopically-labelled lipids need to be used before one can assign an indispensable function for sterols and explain the sterol-oleic acid interaction in $R$. palustris.

There is as yet no explanation for the role of oleic acid in the synthesis of nonsaponifiable lipids. Kodicek (1959) observed that ${ }^{14} \mathrm{C}$-fatty acids from yeast were incorporated more effectively $(11.9 \%)$ into the non-saponifiable lipids of yeast than 
was ${ }^{14} \mathrm{C}$-acetate $(1.7 \%)$, despite the apparent inability of the yeast to degrade the fatty acids to acetate. Bloch \& Amdur (Asselineau, personal communication, 1962) observed similarly that ${ }^{14} \mathrm{C}$-acetate was not taken up at all in the non-saponifiable fraction of Azotobacter chroococcum or Escherichia coli.

Table 3. Interaction between oleic acid and ergosterol in annulling inhibition of growth of Rhodopseudomonas palustris

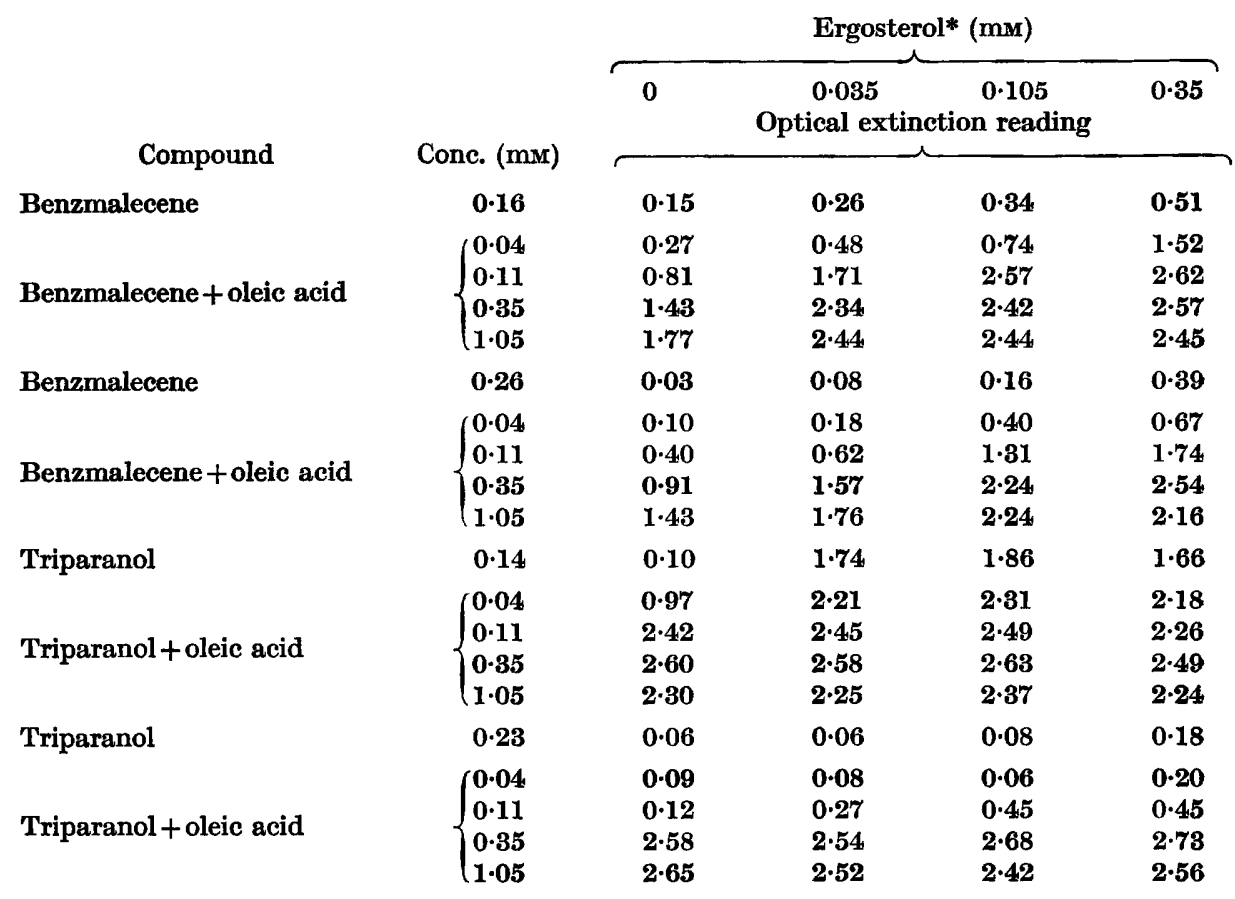

* Pure (homogeneous by thin-layer chromatography).

Holz, Erwin, Wagner \& Rosenbaum (1962) found that mixtures of long-chain fatty acids (oleic, palmitic, stearic) and a synthetic phospholipid spared sterols in the sterol-requiring ciliate Tetrahymena setifera Hz-1. T. pyriformis synthesizes a triterpene but no sterol (Mallory, Gordon \& Conner, 1963) and is inhibited by triparanol. This inhibition is annulled by sterols or long-chain fatty acids (oleic, palmitic, stearic; Holz, Erwin, Rosenbaum \& Aaronson, 1962). Further work may elucidate the peculiar relationship between fatty acids, sterols and terpenes.

This work was supported by grant GM 09103 from the National Institutes of Health, U.S. Public Health Service.

\section{REFERENCES}

Aaronson, S., Bensky, B., Shifrine, M. \& Baker, H. (1962). Effect of hypocholesteremic agents on protozoa. Proc. Soc. exp. Biol., N.Y. 109, 130.

Asselineau, J. (1962). Les Lipides Bactériens. Paris: Hermann et Cie.

Bergmann, W. (1962). Sterols: their structure and distribution. Comparative Biochemistry, III A, pp. 103-162. New York: Academic Press. 
Fiertel, A. \& Krein, H. P. (1959). On sterols in bacteria. J. Bact. 78, 738.

Holmes, W. L. \& Di Tullio, N. W. (1962). Inhibitors of cholesterol biosynthesis which act at or beyond the mevalonic acid stage. Amer. J. clin. Nutr. 10, 310.

Holz, G. G., Jun., Erwin, J., Rosenbaum, N. \& Aaronson, S. (1962). Triparanol inhibition of Tetrahymena, and its prevention by lipids. Arch. Biochem. Biophys. 98, 312.

Holz, G. G., Jun., Erwin, J., Wagner, B. \& Rosenbaum, N. (1962). The nutrition of Tetrahymena setifera $\mathrm{Hz}-1$; sterol and alcohol requirements. J. Protozool. 9, 359.

JENSEN, S. L. (1962). The constitution of some bacterial carotenoids and their bearing on biosynthetic problems. Kgl. Norske Videnskabeis Selskabs Skrifter, nr. 8, 1-199.

Keane, M., Zahalsky, A. C., Hutner, S. H. \& Lubart, K. J. (1963). Defined growth media for Rhodopseudomonas palustris and $\boldsymbol{R}$. spheroides. Studies on Microalgae and Photosynthetic Bacteria, pp. 163-169. Tokyo: University of Tokyo Press.

KoDiceK, E. (1959). Biosynthesis of yeast sterols and the preparation of $\mathrm{C}^{14}$-labelled vitamin $\mathrm{D}_{2}$. In Biosynthesis of Terpenes and Sterols. Ed. by G. E. W. Wolstenholme \& C. M. O'Connor, pp. 173-183. Boston: Little Brown and Co.

Mallory, F. B., Gordon, J. T. \& ConNer, R. L. (1963). The isolation of a pentacyclic triterpenoid alcohol from a protozoan. J. Amer. chem. Soc. 85, 1362.

REbel, G. \& MANDEL, P. (1962). Sur la présence de cholestérol dans les formes $L$ dérivées du bacille Proteus. C.r. hebd. Séanc. Acad. Sci., Paris, 255, 2684.

Sмith, P. F. \& RothblatT, G. H. (1960). Incorporation of cholesterol by pleuropneumonialike organisms. J. Bact. $80,842$.

WooDs, D. D. (1940). The relation of $p$-aminobenzoic acid to the mechanism of the action of sulphanilamide. Brit. J. exp. Path. 21, 74. 